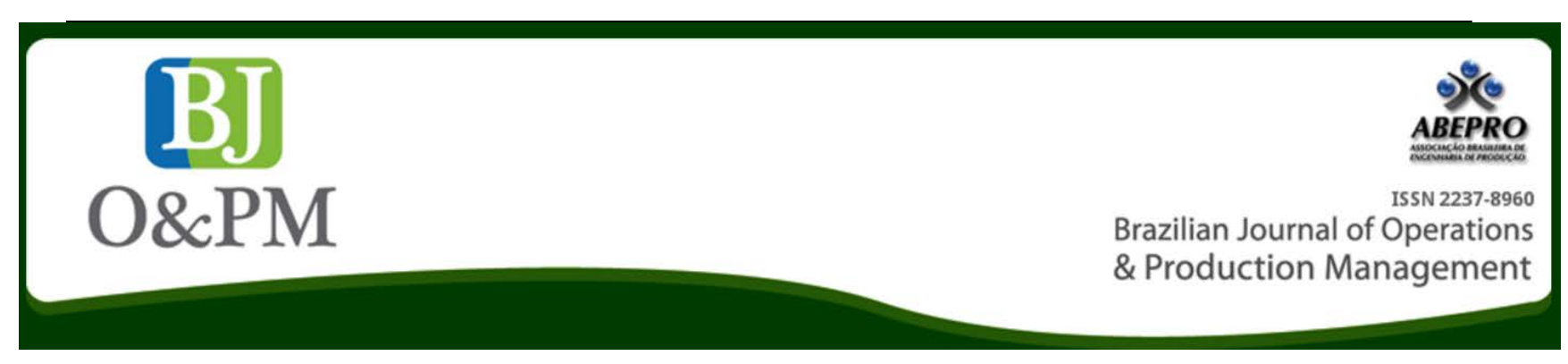

\title{
MODELLING THE HAZARD CONTROL IN A WET PROCESS PLANT- A CASE OF CEMENT PLANT
}

\author{
Kazeem Adekunle Adebiy ; Olasunkanmi Oriola Akinyemib; Adeshinaayomi Lawal Akintan ${ }^{\text {; }}$; Abiola Olufemi Ajayeoba ${ }^{\text {a }}$ \\ a Ladoke Akintola University of Technology, Ogbomoso, Nigeria \\ ${ }^{a}$ Olabisi Onabanjo University, Ago-Iwoye, Nigeria
}

\begin{abstract}
Cement industry is responsible for approximately $5 \%$ of global anthropogenic carbon dioxide emissions emitting nearly $900 \mathrm{~kg}$ of $\mathrm{CO} 2$ for every $1000 \mathrm{~kg}$ of cement produced. Effective control strategies to mitigate these emissions were discussed and a mathematical programming model able to suggest the best cost effective strategy was formulated. Control costs consisting of operating and retrofit costs along with the efficiency of control options are taken into account in the model. A representative case study from the cement industry was considered in order to illustrate the use of the model in giving optimal control strategies. The hazard control model was solved using commercial software called LP_SOLVE (Version 5.5) configured to apply the branch and bound algorithm. Efficiency improvement measures were the considered mitigation option and it was found to be effective options for reduction targets up to $18 \%$. Four efficiency improvement technologies were considered and a reduction of $18 \%$ amounting to almost 100,000 tonnes of emission was achieved with an increase of $14.3 \%$ and $9.1 \%$ in production and operating cost respectively. The findings of this study will help cement plant operators to reduce their emission level by implementing various retrofit options to suite intended targets and subsequently reducing environmental health risk.
\end{abstract}

Keywords: Carbon dioxide emission, efficiency improvement, optimization, reduction target, kiln, cement plant, risk.

\section{INTRODUCTION}

Industrialization provides some of the crucial building blocks of a modern society and makes possible many of the conveniences that we enjoy today. However, the quality of life is measured by more than material possessions; human health and well-being, level of industrialization and the nature of our social systems have important, perhaps fundamental, roles. We realize we are part of a larger picture and our well-being cannot be separated from the well-being of the planet. Ecology which is the study of the interrelationships between organisms and their environment has overtime been popularized as the public began to appreciate the delicate balances that exist in nature and, in some cases, became aware of the stewardship role that they had a responsibility to exercise.

Industrialization and energy use can bring about significant adverse environmental effects and health hazards. One of the most obvious consequences of increased industrialization is the pollution of the air around us. Air pollution is a concern to almost all people today, especially those who live in the metropolitan areas. Air pollution does not respect boundaries-state or nation. It affects people and plant far from its source and hence, a case of severe environmental consequences.

The cement industry of the 21st century is confronted with disparate goals that at first glance seem to conflict. For example, there is enormous pressure to increase profit margins, while at the same time there is considerable public interest in the sustainable and environmentally friendly use of natural resources (Yokoyama et al., 2002). In other words, plant operators find themselves in a situation where they need to react fast and optimally to continuously changing conditions while still meeting various and probably conflicting objectives. Thus, there is a need for tools that bring the plants to their optimal economic performance allowed by the technological, environmental, and contractual constraints. From a technological standpoint, these tools are related to mathematical programming: optimization subject to constraints.

Current trends in energy supply and use cannot be sustained - economically, environmentally or for our society. We can and must change the path that we are on: this will take an energy revolution, with low-carbon energy 
technologies at the center. While all the precise steps in the pathway to a low-carbon economy may not be perfectly clear, we cannot wait for this path to clarify itself. Instead we must proactively move forward with technology research, development and deployment in order to shape the future ourselves.

According to the International Energy Authority World Energy Outlook (1995), worldwide cement production was responsible for seven per cent of the total carbon (IV) oxide emitted around the world Ba-Shammakh et al., (2007). Environmental polices around the world are affecting different industrial sectors and will inevitably affect the cement industry. During the past 10 years, cement industries have been challenged to reduce and effectively control carbon (IV) oxide emissions following resolutions in various greenhouse gas summits like the Kyoto protocol and the recently held summit in Durban, South Africa where governments of different countries became signatories to a resolution to reduce emission by 18\% come year 2015 .

\subsection{LITERATURE REVIEW}

A wide range of studies has been carried out on emission reduction in cement plants, most of the studies however, had only been carried out on dry process cement plants which have lesser emission turnover and sophisticated state of the art manufacturing facilities. The emission peculiarity of wet process plants is attracting a production process switch to the dry process and this has been advocated by various findings in this field of research. The capital intensity of the wet process plant, excellent chemistry of slurry and high turnover of clinker reflect the interests to fashion out a model that can mitigate emission without having to discard the entire process and yet being an environmentally friendly process and a viable business venture.

Meanwhile, the primary objective of cement manufacturers is to increase their profit margins. It is incumbent on them to maintain and align themselves with the Safety, Health and Environmental policies (SHE polices) guiding the establishment of their industry. Scholarly approaches to mitigating emission cannot be over emphasized and yet cannot be regarded as being exhaustive, as so much has been done by researchers to develop optimization models that centre on the subject matter.

Many authors have applied the tools of systems analysis, such as linear and integer programming to the economic evaluation of environmental problems. Ba-Shammakh et al., (2007) did a great deal of work by presenting a mathematical programming model for the reduction of $\mathrm{CO}_{2}$ emissions from a network of power plants. Various $\mathrm{CO}_{2}$ emission reduction strategies were considered in their model. These include efficiency improvement actions, fuel balancing, and fuel switching. However, $\mathrm{CO}_{2}$ capture processes were not included in their study. A mathematical model using a Mixed Integer Non Linear Program (MINLP) was adopted. Various emission targets were arrived at by altering system factors. The results from their study indicated that applying several strategies for increasing the power plant efficiency is an effective way for reducing $\mathrm{CO}_{2}$ emissions. Their optimisation results showed that overall $\mathrm{CO}_{2}$ emissions can be reduced by $1 \%$ by adjusting current operational level without having to change the fleet structure (fuel balancing). Fuel balancing also results in a reduction of operating costs by about $1.5 \%$. However, for further $\mathrm{CO}_{2}$ emission reduction (e.g., by greater than 6\%, Canada's Kyoto target), it will be necessary to employ structural changes such as fuel switching. Fuel switching involving structural changes to the fleet was considered as the best option for $\mathrm{CO}_{2}$ reduction, especially if the reduction target is $10 \%$ or above. Applying technologies for efficiency improvement was also advocated as an attractive option to reduce $\mathrm{CO}_{2}$ emissions, especially at small reduction targets such as around $5 \%$.

Mohammed et al., (2008) conducted a study on the effective control strategies to mitigate $\mathrm{CO}_{2}$ emissions for a dry process cement plant and a mathematical programming model capable of suggesting the best cost effective strategy was outlined. Control costs consisting of operating and investment costs along with the efficiency of control options were taken into account in the model. A representative case study from the cement industry was considered in order to illustrate the use of the model in giving optimal control strategies. Efficiency improvement measures were found to be effective options for reduction targets up to $10 \%$. The model suggested that fuel switching and carbon capture must be considered at reduction targets higher than $10 \%$. The cost of cement production was shown to increase dramatically with an increase in reduction target. This research did not consider the use of other liquid fuel which could have presented a significant turn-around to the results found.

Ogbeide (2010) developed an optimization model using a mixed integer linear programming to mitigate $\mathrm{CO}_{2}$ emissions for a semi-dry process cement plant located in south west, Nigeria as a case study to evaluate the results of various modifications on cement plants operation. An economic model which objective was to highlight the best selection strategy to reduce $\mathrm{CO}_{2}$ emissions with the least cost was developed using the industry data. The model was solved using a Branch and Bound algorithm and coded in GAMS. The cement Plant achieved a significant result of 23.6 per cent reduction in $\mathrm{CO}_{2}$ emissions per tonne of cement produced. The results were achieved mainly by applying a progressive approach prioritizing project implementation effort and feasibility. For $1 \%$ reduction target, the optimizer chose to apply the technology of high efficient motors and 
drives. The cost of production increases by about $2 \%$. A second improvement technology was applied at a reduction target of $5 \%$. No fuel switching was applied up to $10 \%$ where efficiency improvements technologies are applied with an increase of about $7.3 \%$ in the cost. For a $20 \%$ reduction target, fuel switching, from coal to natural gas, was selected to be applied with only one technology for efficiency improvement. This technology is installation of high efficient motors and drives with a proportionate increase in cost by about $17.4 \%$.

Al-Ali et al., (2008) developed a mixed integer programming model for the selection of optimal air pollution reduction strategies for refineries to achieve a given pollution level. The model considered both costs and environmental impacts and was numerically tested on an industrial scale refinery case study. Three mitigation alternatives (fuel switching, sulphur oxides capturing, and nitrogen oxides capturing) were considered. Reduction of a specific pollutant was achieved by a given mitigation for a specific unit in the refinery. This was achieved through the use of different mitigation alternatives for different units in the refinery. It was found that a $60 \%$ reduction level in all pollutants can be achieved by an increase of $7.4 \%$ in cost. Their study however, assumed that the combustion source of unit furnaces is the major contributor of $\mathrm{CO}_{2}$ emissions. However, refinery process units and hydrogen production systems represent a considerable source of $\mathrm{CO}_{2}$ emissions as well and these were not considered in their research.

Elkamel et al., (1998) presented an optimization model that selects pollution control strategies in order to meet environmental standards in a cost effective way. The model took into account the retrofit selection case. It considered long term parameters that might be due to the development of new sources of emission, expansion of the industry and changes in environmental regulations. The solution to the model presented the best adaptive for dealing with these changes. The model was designed such that it may suggest the installation of new controls on existing or new emission sources or it may suggest the combination of new sources with old sources under existing controls. The model was solved using binary integer programming technique. The model was then applied for various levels of reduction in sulphur dioxide and minimum control cost was obtained for each case.

Regulatory and governmental agencies have done a great work on the subject matter. They realized themselves as a key player in mitigating the effects of greenhouse gases and have since instituted various research organs to identify sources of emission, investigate the peculiarities of these emissions and as well proffer roadmaps that seek to forestall the continued depletion of our global habitat. The United State environmental protection agency (EPA) has been at the forefront of this and their publications serve as a great tool towards achieving an "Eldorado" of a globe we all are craving for. In the EPA, 1994 publication, various emission sources particular to the cement plant were identified. These include particulate matter, oxides of nitrogen and sulphur as well as carbon dioxide. The emission factors of a series of cement plants were computed. Coupled with their research work was the comparison of the potency of respective emission mitigation equipment installed at the facilities which served as a source case-studies. The efficiency of the fabric filter was weighed against that of the electrostatic precipitator and other emission capturing equipment. The results of this study are summarized in the table 2.0 below.

International Environmental Agency, IEA (1999) have focused on potential cement industry emissions reductions. Using different scenarios, baseline emissions and future demand forecasts, they nevertheless reached broadly similar conclusions, and the following were highlighted as mitigation options:

1. Thermal and electric efficiency - deployment of existing state of the art technologies in new cement plants, and retrofit of energy efficiency equipment where economically viable.

2. Alternative fuels - use of less carbon-intensive fossil fuels and more alternative (fossil) fuels and biomass fuels in the cement production process. Alternative fuels include wastes that may otherwise be burnt in incinerators, landfilled or improperly destroyed.

3. Clinker substitution - substituting carbon intensive clinker, an intermediate in cement manufacture, with other lower carbon materials with cementitious properties.

4. Carbon capture and storage (CCS) - capturing $\mathrm{CO}_{2}$ before it is released into the atmosphere and storing it securely so it is not released in the future.

\subsection{CARBON (IV) OXIDE EMISSIONS IN CEMENT INDUSTRY}

The main sources of carbon dioxide in cement manufacturing are:

- Combustion of fossil fuel and;

- Limestone calcination.

Other sources, such as the electricity (as in the case of Nigeria, where electricity is chiefly generated from gas and steam plants) and mobile equipment, that represent a small contribution to the total $\mathrm{CO}_{2}$ generated by the cement manufacturing and will therefore not be accounted for in this study. Approximately, half of the $\mathrm{CO}_{2}$ emitted by the cement industry originates from the fuel and half from the calcinations (chemical reaction) that will convert raw materials into clinker. 


\subsection{CARBON DIOXIDE EMISSIONS FROM FUEL USE}

The cement companies use different sources of fuel as identified earlier. Among the elements that make up the cement kiln, fuel carbon and hydrogen are the elements that contribute the most energy during the combustion process. Other elements, such as sulphur and nitrogen oxides, are also present in the combustion process and not only represent a small contribution to the energy process, but also represent a considerable environmental concern. Table 1: Estimated emission factors for cement kilns (US EPA, 1994)

\begin{tabular}{|c|c|c|c|c|c|}
\hline \multirow[t]{3}{*}{ Kiln process } & \multirow{3}{*}{$\begin{array}{l}\text { Fuel requirement } \\
\mathrm{j} / \mathrm{Mg} \\
\text { (MMBtu/ton) }\end{array}$} & \multicolumn{4}{|c|}{$\mathrm{CO}_{2}$ Emission Factor } \\
\hline & & \multicolumn{2}{|c|}{ Fuel combustion } & \multirow{2}{*}{$\begin{array}{l}\text { For } \\
\mathrm{CaCO}_{3} \\
\mathrm{Kg} / \mathrm{Mg} \\
\text { (Lb./Ton) }\end{array}$} & \multirow{2}{*}{$\begin{array}{l}\text { Total } \\
\mathrm{Kg} / \mathrm{Mg} \\
\text { (Lb./Ton }\end{array}$} \\
\hline & & $\begin{array}{l}\mathrm{Kg} / \mathrm{j} \\
\text { (Lb./MMbtu) }\end{array}$ & $\begin{array}{l}\mathrm{Kg} / \mathrm{Mg} \\
\text { (Lb./Ton) }\end{array}$ & & \\
\hline \multicolumn{6}{|l|}{ Coal fired } \\
\hline Wet & $\begin{array}{l}6.00 \times 10^{\wedge} 9 \\
(5.14)\end{array}$ & $\begin{array}{l}0.100 \times 10^{\wedge}-6 \\
(233)\end{array}$ & $\begin{array}{l}600 \\
(1,200)\end{array}$ & $\begin{array}{l}500 \\
(1,000)\end{array}$ & $\begin{array}{l}1,100 \\
(2,200)\end{array}$ \\
\hline Dry & $\begin{array}{l}5.59 \times 10^{\wedge} 9 \\
(4.82)\end{array}$ & $\begin{array}{l}0.100 \times 10^{\wedge}-6 \\
(233)\end{array}$ & $\begin{array}{l}560 \\
(1,100)\end{array}$ & $\begin{array}{l}500 \\
(1,000)\end{array}$ & $\begin{array}{l}1,100 \\
(2,200)\end{array}$ \\
\hline Pre-heater & $\begin{array}{l}4.24 \times 10^{\wedge} 9 \\
(3.65)\end{array}$ & $\begin{array}{l}0.100 \times 10^{\wedge}-6 \\
(233)\end{array}$ & $\begin{array}{l}430 \\
(850)\end{array}$ & $\begin{array}{l}500 \\
(1,000)\end{array}$ & $\begin{array}{l}930 \\
(1,700)\end{array}$ \\
\hline \multicolumn{6}{|l|}{ Gas fired } \\
\hline Wet & $\begin{array}{l}6.00 \times 10^{\wedge} 9 \\
(5.14)\end{array}$ & $\begin{array}{l}0.603 x \\
10^{\wedge}-6 \\
(140)\end{array}$ & $\begin{array}{l}360 \\
(720)\end{array}$ & $\begin{array}{l}500 \\
(1,000)\end{array}$ & $\begin{array}{l}860 \\
(1,700)\end{array}$ \\
\hline Dry & $\begin{array}{l}5.59 \times 10^{\wedge} 9 \\
(4.82)\end{array}$ & $\begin{array}{l}0.603 \times 10^{\wedge}-6 \\
(140)\end{array}$ & $\begin{array}{l}340 \\
(680)\end{array}$ & $\begin{array}{l}500 \\
(1,000)\end{array}$ & $\begin{array}{l}840 \\
(1,700)\end{array}$ \\
\hline Pre-heater & $\begin{array}{l}4.24 \times 10^{\wedge} 9 \\
(3.65)\end{array}$ & $\begin{array}{l}0.603 x \\
10^{\wedge}-6 \\
(140)\end{array}$ & $\begin{array}{l}260 \\
(510)\end{array}$ & $\begin{array}{l}500 \\
(1,000)\end{array}$ & $\begin{array}{l}600 \\
(1,500)\end{array}$ \\
\hline
\end{tabular}

\subsection{CARBON DIOXIDE FORMED BY CALCINATION}

A large percentage of cement plants are located close to their source of calcium oxide. This is an essential requirement since limestone represents about two-thirds of the clinker composition by mass. A typical clinker raw mix is made up of approximately 80per cent limestone.

During the clinkering process limestone will suffer calcination and $\mathrm{CO}_{2}$ will be formed. The limestone chemical reaction can be expressed by the equation below:

$$
\begin{aligned}
& \mathrm{CaCO}_{3} \rightarrow \mathrm{CaO}+\mathrm{O}_{2} \\
& 1 \mathrm{~kg} \rightarrow 0.56 \mathrm{~kg}+0.44 \mathrm{~kg}
\end{aligned}
$$

The percentage of calcium oxide $(\mathrm{CaO})$ in clinker is usually between 64 and 67 percent.
The amount of $\mathrm{CO}_{2}$ generated by the process varies based on the specific loss of the raw materials (limestone) on ignition (Bhatty et al., 2004).

Mass balance and direct measurement are the basic means of quantifying the mass flow of the constituents of the cement making process. Mass balance accounts for the mass transfer of various constituents of a chemical process such as the production of cement. It represents the mass flow of various inputs; raw material and energy and the yielding output. It is a balanced circuit where all input resources are accounted for in terms of desired output (clinker) and undesired output (emissions; particulate dust, $\mathrm{CO}_{2}, \mathrm{NO}_{x^{\prime}} \mathrm{SO}_{2}$ etc.). Represented in the diagram below is the typical mass balance of a cement production. 


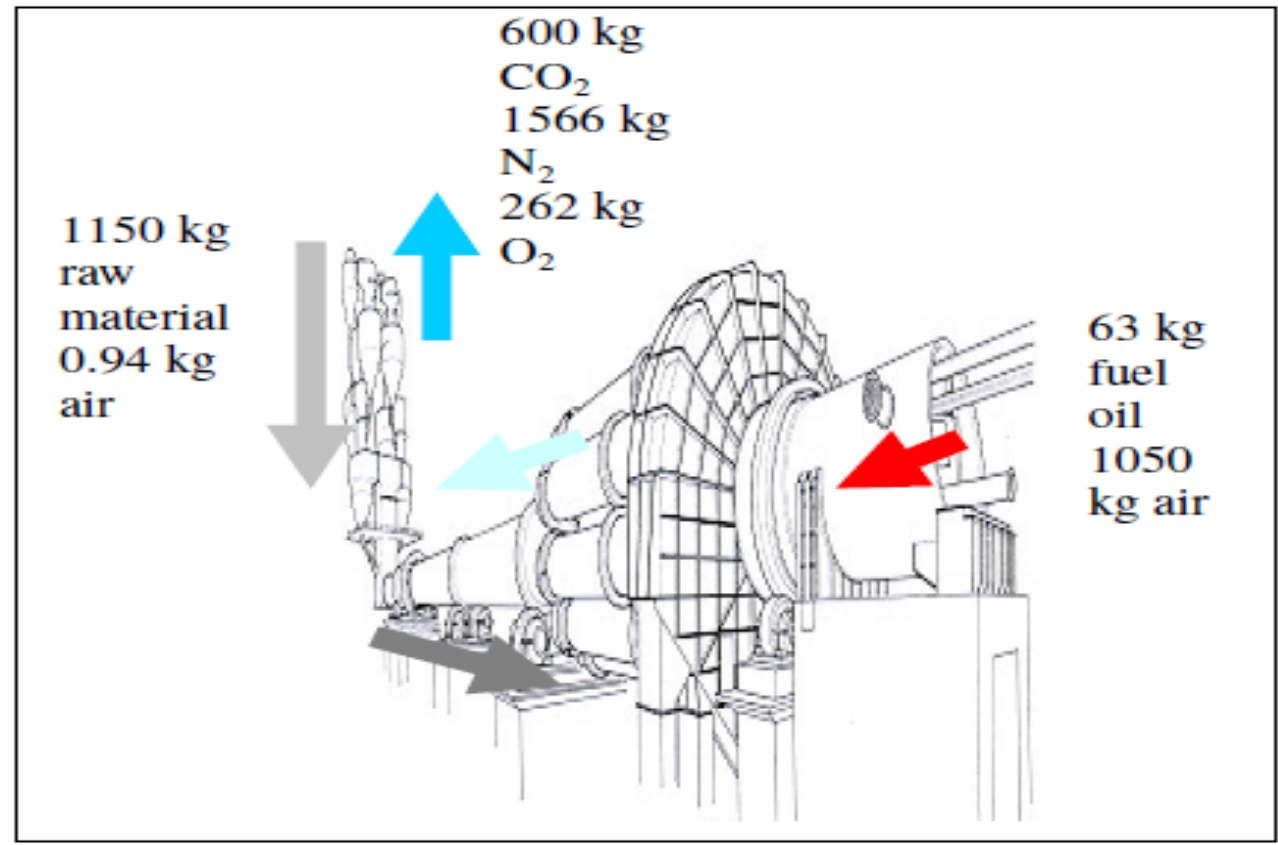

Figure 1: Typical cement plant mass balance (IEA, 1999).

Figure 1 above shows process flow diagram for the cement manufacturing process, showing energy and heat consumption or inputs, as well as gaseous and particulate emissions.

\section{$1.5 \mathrm{CO}_{2}$ MITIGATION OPTIONS}

Manufacturing industries and business organizations are set up primarily to meet the thirst or need for a particular commodity. Apart from this primary objective of societal satisfaction, the main aim of such organizations or manufacturing industries is to make profit, maximize profit, or minimize cost. In these cases, huge investments are been made in several aspects such as start-up capital, equipment, and machines. These business and organizational objectives should not however be hinged majorly on themselves as that will amount for unaccountability and selfishness but rather on a goal of collective sustainability of their businesses as well as the environment in which the organizations operate.

Cement no doubt, is a much needed commodity and our development as a nation is not far-fetched from our infrastructural strength in terms of buildings and other physical infrastructure. Cement therefore plays a critical role in this regard. Cement could qualify as the most needed commodity to human after food, as it serves as a major constituent in the making of human shelter. Its production and availability cannot be toyed with but alas, an accompanying pollution is imminent.

This presents a choice, to save the world and have no cement i.e. infrastructure or produce cement and its accompanying menace; pollution. Since we cannot imagine a world without these buildings that house us, the roads which we ply and other beautiful physical structures, cement production is utmost and a means of mitigating the pollutions could serve as a tool to maintain an infrastructural and ecological balance. Hence, a need for mitigating the resulting greenhouse gases-

Ongoing scientific research into the effects of anthropogenic carbon dioxide $\left(\mathrm{CO}_{2}\right)$ emissions is expected to result in ever increasing restrictions on greenhouse gas emissions with the potential for a net zero carbon economy well before the end of the century (Choate, 2003). Initially, carbon constraints will cause a reduction in the growth of emissions, rapidly approaching constant rates of global emission. Over decades, the rate of emissions should start to drop and gradually trend to less than $30 \%$ of current global emissions. Even then, the $\mathrm{CO}_{2}$ concentration in the atmosphere will still be rising also much more slowly than today (Mohammed et al., 2008).

During the last 20 years, environmental matters have had more influence in different global agreements; however, since solutions could result in a reduction in the profit margin of certain multinational corporations or adversely impact the economy of industrialized countries, the only possible solution is one that will offer environmental gains and strong business opportunities [5].

Choate, (2003), Mohammed et al., (2008), Ogbeide, (2010), EPA, (2010) and Worrell et Galitsky, (2008) identified possible mitigation potentials for cement manufacturing industries. The results of their findings can be chiefly categorized under the headings: 
1. Applying efficiency improvement technologies to reduce $\mathrm{CO}_{2}$ emissions;

2. Switching to less carbon content fuel such as from coal to natural gas;

3. Retrofitting an emission capture technology;

4. Shifting to a more energy efficient process (e.g. from wet and long dry to a preheater/precalciner process); and

5. Applying lower clinker/cement ratio (increasing the ratio additives/cement): blended cements.

\section{OPTIMIZATION MODEL}

The mathematical model consists of an objective function to be minimized subject to equality and inequality constraints. The objective of the model is to find the best strategy or mix of strategies to reduce $\mathrm{CO}_{2}$ up to a certain target with minimum overall cost for cement production while meeting the demand.

The objective function to be minimized can be written as:

$$
Z(\$ / y)=\sum_{r} C_{r} R_{r}+\sum_{i} \sum_{f} C_{f} P_{f}+\sum_{i} \sum_{f} R_{f} X_{f}+\sum_{i} \sum_{e} C_{\dot{e}} Y_{\dot{e}}
$$

$Z=$ annualized capital and operating cost of the cement plant $(\$ / y r)$

$C_{r}$ : cost of purchasing raw material $\mathrm{r}(\$ /$ tonne)

$\mathrm{R}_{\mathrm{r}}$ : Purchased amount of raw material $r$ (tonne/yr)

$C_{\text {if }}$ : Operating cost for a unit i with fuel $\mathrm{f}(\$ /$ tonne)

$P_{f}$ : Amount produced from unit i using fuel $\mathrm{f}$ (tonne/yr)

$R_{\text {if }}$ : Retrofit cost for switching unit i to run with another fuel $f(\$ / y r)$

$X_{f}$ : Binary variable representing switching or not

$C_{i e}$ : Cost of applying efficiency improvement technology (e) on unit i $(\$ / y r)$

$Y_{\text {ie }}$ : Binary variable representing applying efficiency improvement technology (e) or not

The first term in the objective function represents the cost associated with purchasing the raw material. The second term takes into account the operating cost for different units. The cost of switching to less carbon content fuel is shown in the third term. The fourth term represents the cost associated with applying efficiency improvement technologies. A binary variable is defined for each $\mathrm{CO}_{2}$ mitigation option under study.

\section{$2.1 \quad$ CONSTRAINTS}

The constraints for demand satisfaction, and $\mathrm{CO}_{2}$ emissions reduction are given in details as follows:

\section{(a) Demand satisfaction:}

This constraint simply says that total cement produced should be greater than or equal to the demand.

$$
\sum_{i} \sum_{f} P_{f} \geq \text { Demand }
$$

\section{(b) Fuel selection:}

Each unit $i$ has to run with only one fuel $f$. For that reason, a binary variable is introduced to represent the type of fuel used in a given unit.

$$
\sum_{f} X_{i f}=1 \quad \forall i
$$

\section{(c) Emission constraint:}

The $\mathrm{CO}_{2}$ emitted from all units must satisfy a $\mathrm{O}_{2}$ reduction target.

Different technologies, e, to improve the efficiency are represented in the mathematical model. It is assumed that the effect of these technologies is additive.

$$
\sum_{i} \sum_{f} \boldsymbol{O} \quad 2 \dot{f}\left(1-\sum_{e} \varepsilon_{\dot{e}} Y_{\dot{e}}\right) P_{f} \leq\left(\begin{array}{rr}
1-\% O & 2
\end{array}\right) O_{2}
$$

Where:

$\mathrm{CO}_{2 i f}: \mathrm{CO}_{2}$ emissions from unit $i$ using fuel $f$ (tonne per tonne cement produced)

$\varepsilon_{\mathrm{ie}}$ : percent gain in efficiency associated with applying technology $e$ on unit $i$.

$\mathrm{Y}_{\mathrm{ie}}$ : binary variable for applying efficiency improvement technology $e$ or not.

$\% \mathrm{CO}_{2}$ : reduction target

$\mathrm{CO}_{2}$ : Current $\mathrm{CO}_{2}$ emissions (tonne/yr) 


\section{(d) Non-negativity constraints:}

The amount produced must be greater than zero

$$
P_{f} \geq 0 \quad \forall i
$$

The emission constraint is nonlinear, the resulting Mixed Integer Non Linear Programme is linearized and solved using LPSOLVE version 5.5 configured to implement a binary branch and bound algorithm.

\subsection{BRANCH AND BOUND ALGORITHM}

Mixed Integer Linear Program (MILP) differs from Linear Programs (LP) in that its variables are restricted to have values of either 0 or 1 . Mixed integer programming problems are combinatorial optimization problems that are difficult to solve. This difficulty is due to the exponential growth of solution space with a linear increase in the number of variables in the model. For instance, for a problem with twenty binary variables, the number of possible linear programs (LP) that one has to consider in an exhaustive enumeration approach is more than $1,000,000\left(2^{x}\right)$. If the number of variables is 30 , then the numbers of LPs that have to be considered would be more than one billion. The combinatorial explosion is even worse for general integer variables that can take on even more values than just the two possibilities for binary variables. It is easy to construct problems in which the number of solutions is greater than the total number of atoms in the universe! Enumeration just won't work for most real-world problems - we need a better way of tackling the combinatorial explosion (Ogbeide, 2010).

Branch-and-bound is essentially a strategy of "divide and conquer". The idea is to partition the feasible region into more manageable subdivisions and then, if required, to further partition the subdivisions.

In general, there is a number of ways to divide the feasible region, and as a consequence there are a number of branch-and-bound algorithms. This research work is hinged on binary branch \& bound algorithm. It involves solving a (potentially) large number of (related) linear programming problems in its search for an optimal integer solution.

The method is based on the observation that the enumeration of integer solutions has a tree structure. The main idea in branch and bound is to avoid growing the whole tree as much as possible, because the entire tree is just too big in any real problem. Instead, branch and bound grows the tree in stages, and grows only the most promising nodes at any stage. It determines which node is the most promising by estimating a bound on the best value of the objective function that can be obtained by growing that node to later stages. The name of the method comes from the branching that happens when a node is selected for further growth and the next generation of children of that node is created. The bounding comes in when the bound on the best value attained by growing a node is estimated. Hoping that in the end, only a very small fraction of the full enumeration tree is grown and a feasible and optimal solution is reached.

\subsection{CASE STUDY}

For the purpose of this research, the model above was tamed to reflect the case study plant. The cement plant under study is a wet process plant located in south western Nigeria. The plant was installed and running a dual firing system for natural gas and heavy oil. However, the year for which data was gotten; natural gas was used as a sole fuel owing to management decision bothering on availability, neatness, effect on refractory walls as well as economics and cost concerns. Therefore, fuel switching was not considered as possible mitigation option.

Carbon capture technology hasn't been found running on any cement plant all over the world, the technology is said to be in pilot stage at various research centers but however, it has been demonstrated in power plants and the prospects that it will work in a cement plant is high.

Having left out fuel switching and carbon capture, the following technologies were retrofitted for each emission unit:

\section{Adjustable Speed Drive}

2. Kiln Drive Efficiency Improvement

3. Recipricating Grate Coolers

4. Process Control And Management System

The following data were studied, and in effect four efficiency improvement technologies were retrofitted and the aim is to minimize the cost of cement manufacturing while reducing carbon dioxide emission by a fixed target.

- Cement output $=680,087$ Tonnes

- $\quad$ Clinker output $=568,470$ Tonnes

- Annual emission of $\mathrm{CO}_{2}=549,471$ Tonnes

- $\quad$ Annualized cost $=\$ 27.84 * 10^{\wedge} 6$

- Emission units: 2

- Process type: wet process

\section{RESULTS}

Represented in the Table 2 below are results of the model at various reduction targets expressed as a percentage of the present emission level, also included in the table are the 
technologies chosen by the model to fulfill target emission levels and percentage increase in production and operating costs.

Table 2: Mathematical model results

\begin{tabular}{|c|c|c|c|}
\hline $\begin{array}{l}\text { REDUCTION TARGETS } \\
\text { (\%) }\end{array}$ & $\begin{array}{l}\text { M I T I G A T I O N } \\
\text { OPTION(S) } \\
\text { SELECTED BY MODEL }\end{array}$ & $\begin{array}{l}\text { PERCENTAGE INCREASE } \\
\text { IN PRODUCTION COST }\end{array}$ & $\begin{array}{l}\text { PERCENTAGE INCREASE } \\
\text { IN OPERATING COST }\end{array}$ \\
\hline 0.0 & - & $0.0 \%$ & $0.0 \%$ \\
\hline 1.0 & $Y_{12}, Y_{13}$ & $8.6 \%$ & $5.1 \%$ \\
\hline 2.0 & $Y_{12}, Y_{13}$ & $8.6 \%$ & $5.1 \%$ \\
\hline 3.0 & $Y_{12}, Y_{13}, Y_{23}$ & $8.7 \%$ & $5.2 \%$ \\
\hline 4.0 & $\mathrm{Y}_{12}, \mathrm{Y}_{22}$ & $8.7 \%$ & $5.2 \%$ \\
\hline 5.0 & $Y_{12}, Y_{22}$ & $8.7 \%$ & $5.2 \%$ \\
\hline 6.0 & $Y_{12}, Y_{22}, Y_{23}$ & $8.8 \%$ & $5.3 \%$ \\
\hline 7.0 & $Y_{12}, Y_{14}, Y_{22}$ & $9.1 \%$ & $5.5 \%$ \\
\hline 8.0 & $Y_{12}, Y_{22}, Y_{24}$ & $9.1 \%$ & $5.5 \%$ \\
\hline 9.0 & $Y_{12}, Y_{14}, Y_{22}, Y_{24}$ & $9.6 \%$ & $5.8 \%$ \\
\hline 10.0 & $Y_{12}, Y_{14}, Y_{22}, Y_{24}$ & $9.6 \%$ & $5.8 \%$ \\
\hline 11.0 & $\begin{array}{l}Y_{12^{2}}, Y_{13^{\prime}} Y_{144^{\prime}}, Y_{22} \\
Y_{23} Y_{24}\end{array}$ & $9.7 \%$ & $5.9 \%$ \\
\hline 12.0 & $\begin{array}{l}Y_{11}, Y_{12}, Y_{14}, Y_{22} \\
Y_{24}\end{array}$ & $11.9 \%$ & $7.4 \%$ \\
\hline 13.0 & $\begin{array}{l}Y_{11}, Y_{12}, Y_{14}, Y_{22} \\
Y_{24}\end{array}$ & $11.9 \%$ & $7.4 \%$ \\
\hline 14.0 & $\begin{array}{l}Y_{11}, Y_{12}, Y_{14}, Y_{22} \\
Y_{24}\end{array}$ & $14.2 \%$ & $9.0 \%$ \\
\hline 15.0 & $\begin{array}{l}Y_{11^{\prime}}, Y_{12}, Y_{144^{\prime}}, Y_{21} \\
Y_{22} Y_{24}\end{array}$ & $14.2 \%$ & $9.1 \%$ \\
\hline 16.0 & $\begin{array}{l}Y_{11,}, Y_{12}, Y_{22}, Y_{14} \\
Y_{21}, Y_{22}, Y_{23}, Y_{24}\end{array}$ & $14.3 \%$ & $9.1 \%$ \\
\hline 17.0 & $\begin{array}{l}Y_{11}, Y_{12}, Y_{22}, Y_{14} \\
Y_{21}, Y_{22}, Y_{23}, Y_{24}\end{array}$ & $14.3 \%$ & $9.1 \%$ \\
\hline 18.0 & $\begin{array}{l}Y_{11}, Y_{12}, Y_{22}, Y_{14} \\
Y_{21}, Y_{22}, Y_{23}, Y_{24}\end{array}$ & $14.3 \%$ & $9.1 \%$ \\
\hline
\end{tabular}

Where:

$\mathrm{Y}_{11}$-Adjustable Speed Drive For Unit 1

$\mathrm{Y}_{12}$-Kiln Drive Efficiency Improvement For Unit 1

$\mathrm{Y}_{13}$-Recipricating Grate Coolers For Unit 1

$\mathrm{Y}_{14}$-Process Control And Management System For Unit 1

$\mathrm{Y}_{21}$-Adjustable Speed Drive For Unit 2

$\mathrm{Y}_{22}$-Kiln Drive Efficiency Improvement For Unit 2

$\mathrm{Y}_{23}$-Recipricating Grate Coolers For Unit 2

$\mathrm{Y}_{24}$-Process Control And Management System For Unit 2

Where $Y_{11}$ to $Y_{24}$ are binary variables. 


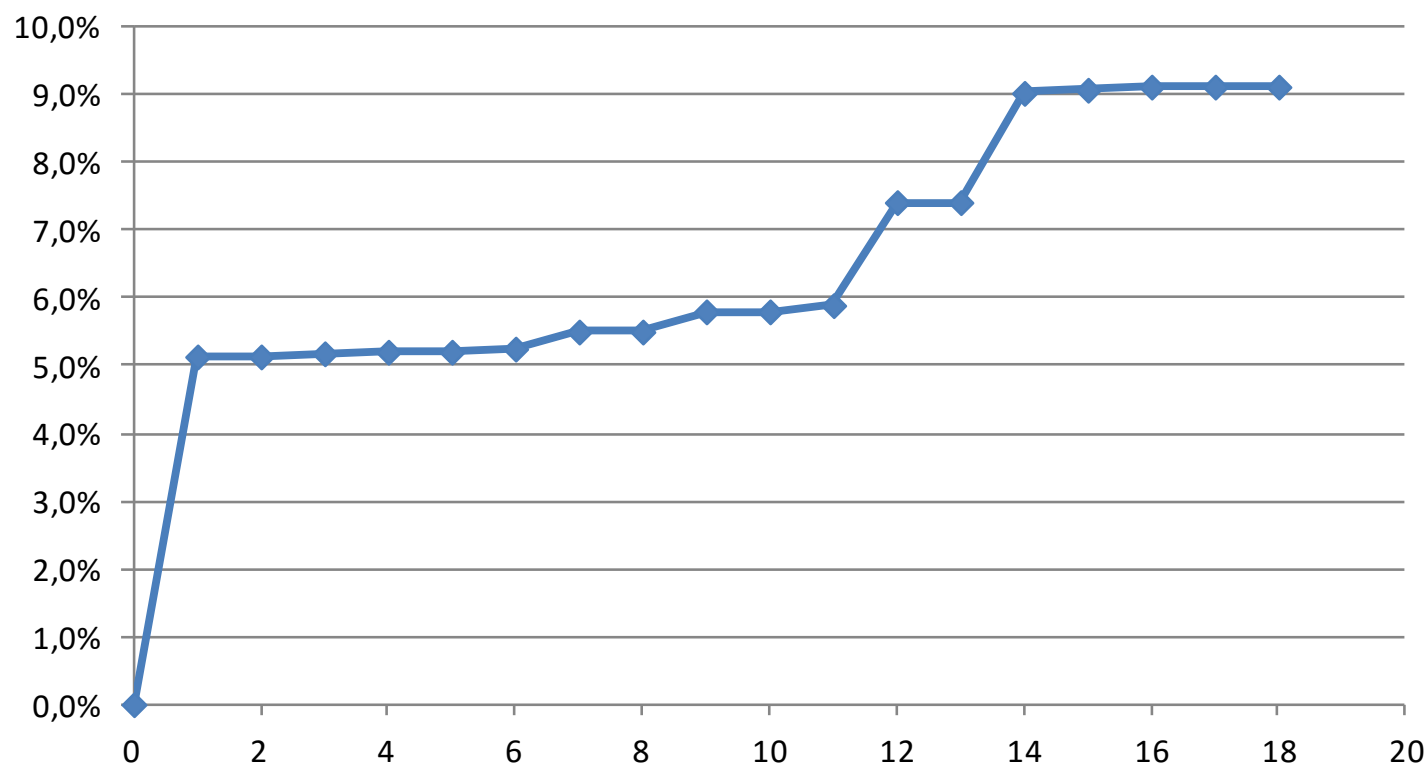

Figure 2: Percentage increase in operating cost versus reduction target

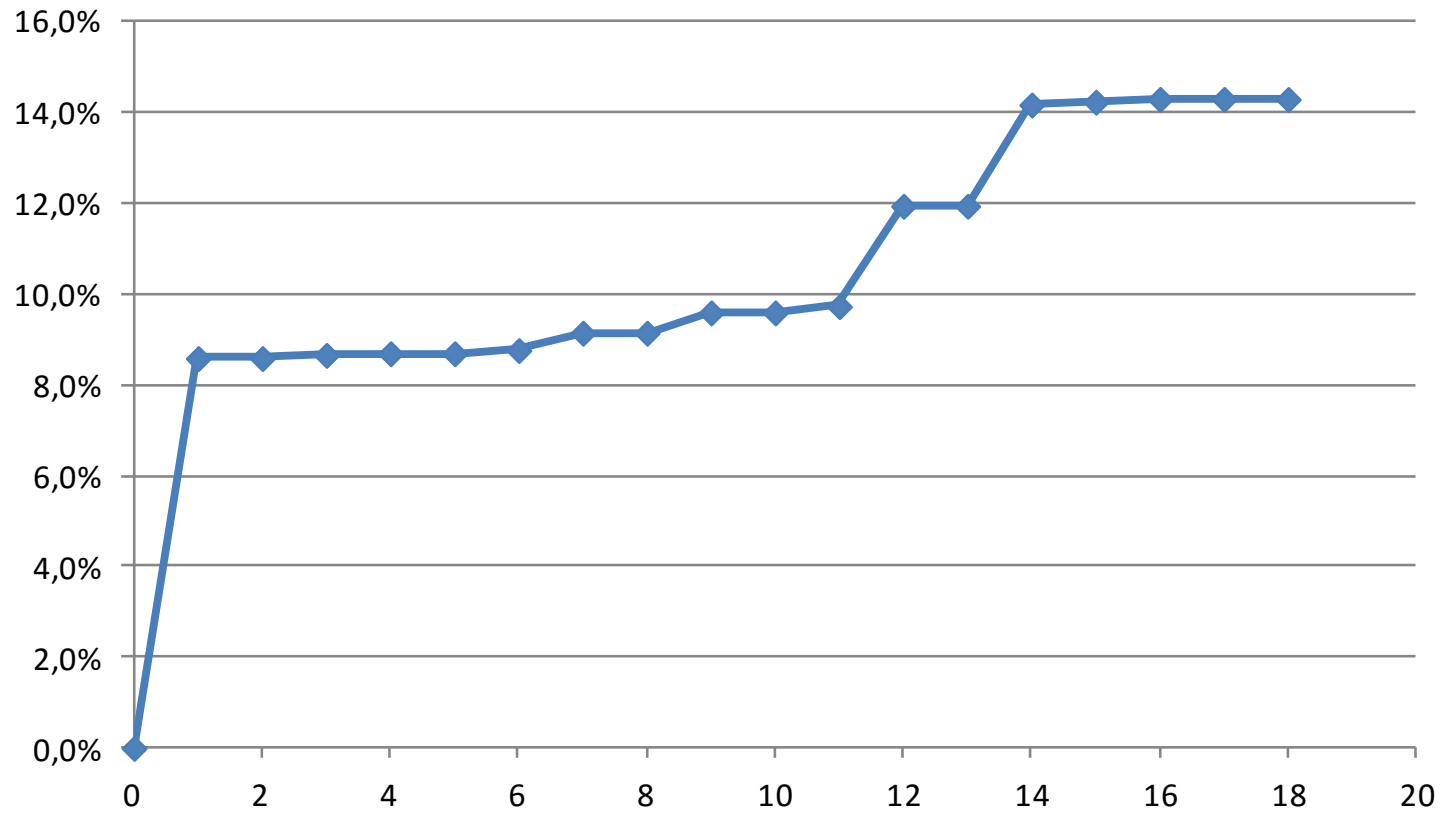

\section{DISCUSSION}

At a reduction targets of 1 to $2 \%$ as shown in Table 2, the model chose the retrofit of Kiln Drive Efficiency Improvement and Recipricating Grate Coolers for unit 1. At this target, retrofit are only to be carried out on Unit 1 as suggested by the model. This will therefore bring about $8.6 \%$ increase in total production cost and $5.1 \%$ increase in operating cost as shown in Table 2. Cement plant operators targetting this level of reduction can choose these technologies. At $3 \%$ reduction target, the model chose the retrofit of 3 technologies; Kiln Drive Efficiency Improvement for Unit 1 and -Recipricating Grate Coolers for Units 1 and 2. Resulting into $8.7 \%$ increase in total production cost and $5.2 \%$ increase in operating cost. At 4 and $5 \%$ reduction targets however, the model chose the retrofit of the same technology for each kiln; Kiln Drive Efficiency Improvement For Kilns 1and 2 as shown in Table 2 resulting in $8.7 \%$ increase in production cost and $5.7 \%$ 
increase in operating cost. At a reduction target of 3 to $5 \%$; 16,648 to 27,748 tonnes of carbon dioxide, the model chose the retrofit of Kiln Drive Efficiency Improvement for Unit 1 and Recipricating Grate Coolers for Unit 1 and 2. At this target, retrofits are to be carried out on Units 1 and 2 as suggested by the model. This amounts to $8.7 \%$ increase in total production cost and $5.2 \%$ increase in operating cost. Cement plant operators targetting this level of reduction can choose these mix of technologies.

It can be inferred from table 2 that at reduction targets of between 1 to $5 \%$, the model chose a mixture of 2 technologies but a rather different mixture of technologies was made at a reduction target of $3 \%$ whereby the model chose three technologies. Kiln Drive Efficiency Improvement for unit 1 and Reciprocating Grate Coolers for Units 1 and 2. This is noteworthy! A dramatic rise in operating cost is observed at a reduction target of $1 \%$ resulting in an $8.6 \%$ increase in production cost and $5.1 \%$ increase in operating cost. This represents the highest cost increase for the least reduction target as shown in figures 3 and 4 . At reduction target of $5 \%(27,748$ tonnes of emission), the model chose the retrofit of Kiln Drive Efficiency Improvement for units $1 \& 2$ bringing about a $8.7 \%$ increase in production cost and $5.2 \%$ increase in operating cost. At 6\% reduction target; 33,297 tonnes of carbon dioxide, the model chose the retrofit of Kiln Drive Efficiency Improvement for Unit s 1and 2 and Recipricating Grate Coolers for Unit 2 as shown in Table 2. At this target, retrofit are to be carried out on both units as suggested by the model. This amounts to $8.8 \%$ increase in total production cost and $5.3 \%$ increase in operating cost. Cement plant operators targetting this level of reduction can choose these mix of technologies.

From Table 2 above, reduction targets of 7 and $8 \%$ are 38,846 and 44,396 tonnes of $\mathrm{CO}_{2}$ however, the model chose the retrofit of 3 different mix of technologies for 7 and $8 \%$ reduction targets respectively. Thereby bringing about the same increase in production and operating costs representing $9.1 \%$ and $5.5 \%$ respectively. At $7 \%$ target, the following retrofits were chosen by the model Kiln Drive Efficiency Improvement for Kilns 1 and 2 and Process Control And Management System for Unit 1 and at $8 \%$ reduction target, the model chose Kiln Drive Efficiency Improvement for Units 1 and 2 and Process Control And Management System for Unit 2. Since both targets bring about the same cost increase, the retrofit of the technologies of $8 \%$ is more economical as a it provides a further reduction from $7 \%$ to $8 \%$ with the same cost implication.

At 9 and 10\%, the model chose the retrofit of Kiln Drive Efficiency Improvement for Units 1 and 2 and Process Control And Management System also for both emission units. This amounts to $9.1 \%$ increase in production cost and $5.8 \%$ increase in operating cost as shown in Table 2 . At $11 \%$ reduction target representing a 61,044 tonnes of emission, the model chose the retrofit of 3 technologies for each units; Kiln Drive Efficiency Improvement, Recipricating Grate Coolers and Process Control And Management Systems for emission units 1 and 2 . Thereby resulting into $9.7 \%$ and $5.9 \%$ increase in production and operating costs respectively. At 12 and $13 \%$ reduction target, the model chose the retrofit of Adjustable Speed Drive for Unit 1,Kiln Drive Efficiency Improvement and Process Control And Management System For Units 1 and 2. Representing 11.9\% and 7.4\% increase in production and operating costs respectively. Of particular interest are reduction targets of 11 to $12 \%$ and 13 to $14 \%$ whereby there is a surge in cost parameters from $9.7 \%$ to $11.9 \%$ production cost, 5.9 to $7.4 \%$ operating cost and 11.9 to $14.2 \%$ production cost and 7.4 to $9.0 \%$ increase in operating cost respectively as represented in figures 2 and 3 respectively. At $15 \%$ reduction target, the model chose Adjustable Speed Drive, Kiln Drive Efficiency Improvement and Process Control And Management Systems all for both units. Representing a $14.2 \%$ and $9.2 \%$ increase in production and operating costs respectively as represented in Table 2.

A reduction target of $18 \%$ is the maximum feasible result that can be achieved with the technologies under consideration thereby bringing about a $9.1 \%$ increase in total production cost and $14.3 \%$ increase in total operating cost. Further reduction targets renders the model infeasible. Hence representing the maximum reduction in emission feasible with the retrofit of these technologies.

\section{CONCLUSION}

Different alternatives discussed in this study can contribute to a significant progress in reducing emissions and energy waste. Improvements and solutions will need to be better coordinated and communicated with the society, government, environmental agencies, and other affiliate institutions. Public and political perception is a long way from full acceptance of the use of alternatives in cement production. Suppose a carbon tax is imposed per tonne of emission say, $\$ 100.18 \%$ of total $\mathrm{CO}_{2}$ emission of the plant amounts to 99,891 tonne estimating a sum of $\$ 9,989,100$ as carbon tax. This carbon tax is almost twice the cost of implementing the findings of this study as an $18 \%$ reduction is achievable with $\$ 5,604,760$. Thereby presenting a better business choice:

Switching from wet to dry process was never chosen because this technology is a natural option for cement plants to reduce cost and increase competitiveness. Actually wet system is not an option for the newer cement plants. But existing wet plants cannot be completely faced out as they still compliment the shortfall in the demand of cement in the country. However, so much can still be done in terms of technological upgrade as it has been proved in this study. 


\section{REFERENCES}

Al-Ali, H. (2008) A Mathematical Programming Model for Achieving Total Emission Control in the Petroleum Refining Industry. International Journal of Oil, Gas and Coal Technology, Vol.1, No. 4, pp.444-463.

Ba-Shammakh, M, A. Elkamel, P.L. Douglas, and E. Croiset. (2007) A Mixed-Integer Non-Linear Programming Model for $\mathrm{CO}_{2}$ Emission Reduction in the Power Generation Sector. International Journal of Environment and Pollution, Vol. 29, No. (1/2/3), pp. 254-273.

Bhatty, J. I., Miller F.M. and Komotha S. (2004) Innovation in Portland cement Manufacturing. Portland Cement Association. pp. 69-76.

Choate, T.W. (2003) Energy and Emission Reduction Opportunities for the Cement Industry. Industrial Technologies Program, U.S Department of Energy, Energy Efficiency and Renewable Energy. 14: 24-29.

Elkamel, A., A. Elgibaly, and W. Bouhamra. (1998) Optimal Air Pollution Control Strategies: The Retrofitting Problem. Advances in Environmental Research, Vol. 2, No. 3, pp.375389.

Mohammed, B.A. Caruso H, Elkamel A, Croiset E, and Douglas P. (2008) Analysis and Optimization of Carbon Dioxide Emission Mitigation Options in the Cement Industry. American Journal of Environmental Sciences, Vol. 4, No. 5, pp. 482-490.

Ogbeide S.O. (2010) Developing an Optimization Model for $\mathrm{CO}_{2}$ Reduction in Cement Production Process. Journal of Engineering Science and Technology Review, Vol. 3 No. 1, pp. 85-88.

Programme IEA Greenhouse Gas R\&D. (1999) The reduction of greenhouse gas emissions from the cement industry. Report Number PH3/7. pp. 25-49.

U.S. Environmental Protection Agency. (1994) Emission factor documentation for AP-42, section 11.6: Portland Cement Manufacturing- Final report. EPA Contract 68-D20159, MRI Project No. 4601-01.

U.S. Environmental Protection Agency. (2010) Available and Emerging Technologies for Reducing Greenhouse Gas Emissions from the Portland cement Industry. Office of Air and Radiation.

Worrell, E and Galitsky, C. (2008) Energy Efficiency Improvement and Cost Saving Opportunities for Cement Making. (Report No. LBNL-54036-Revision), Ernest Orlando Lawrence Berkeley National Laboratory, Berkeley, CA.

Yokoyama, R., Hasegawa, Y. and Ito, K. A. (2002) MILP Decomposition Approach to Large Scale Optimization in Structural Design of Energy Supply Systems. Energy Conversion and Management, Vol. 43, pp.771-790. 